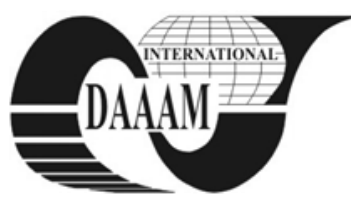

Annals of DAAAM for 2011 \& Proceedings of the 22nd International DAAAM Symposium, Volume 22, No. 1, ISSN 1726-9679 ISBN 978-3-901509-83-4, Editor B. Katalinic, Published by DAAAM International, Vienna, Austria, EU, 2011 Make Harmony between Technology and Nature, and Your Mind will Fly Free as a Bird Annals \& Proceedings of DAAAM International 2011

\title{
ARM POSITION SIMULATION OF PAM BASED ACTUATOR
}

\author{
PITEL, J[an]; NEYDORF, R[udolf] \& BORZIKOVA, J[ana]
}

\begin{abstract}
This paper deals with arm position simulation of the PAM based actuator consisting of two pneumatic artificial muscles (PAMs) in antagonistic connection and four solenoid valves (two for muscles filling and two for muscles emptying). The main point of paper is design and simulation of the model which regards with different dynamic characteristics of the pneumatic artificial muscle by inflation and deflation of compressed air into or from muscle. The model was created and simulated in Matlab's Simulink environment
\end{abstract}

Key words: simulation, actuator, artificial muscles

\section{INTRODUCTION}

The pneumatic actuator with artificial muscles in antagonistic connection was designed and its static and dynamic characteristics were described (Balara \& Balara, 2010, Balara \& Boržíková, 2005). Pneumatic artificial muscles (PAMs) act against themselves and resultant position $\varphi$ of the actuator arm is given by equilibrium of their tensile forces $\left(F_{1}\right.$, $F_{2}$ ) according to different pressures $\left(p_{1}, p_{2}\right)$ in muscles (Fig. 1). If there are equal filling pressures in both muscles, tensile forces of PAMs are equal and system is stabilized in zero initial position. The pressures in muscles are controlled by four ON/OFF solenoid valves: two for muscles filling (inlet solenoid valves SV_i1 and SV_i2) and two for emptying (outlet solenoid valves SV_o1 and SV_o2).

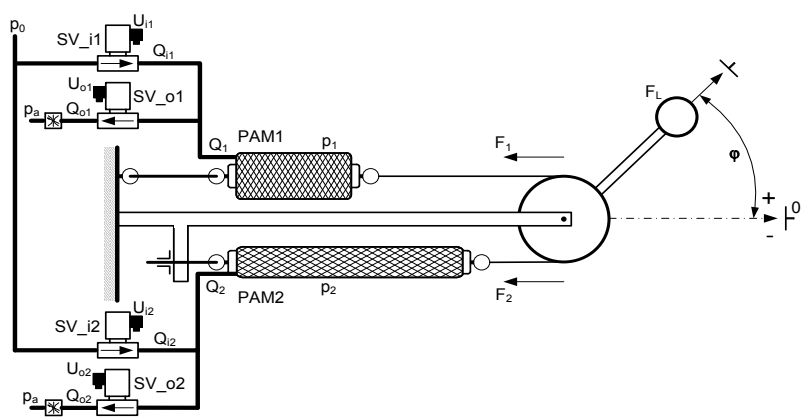

Fig. 1. Rotary actuator with pneumatic artificial muscles

\section{SIMULATION MODEL OF ACTUATOR}

Based on designed block diagram of the actuator (Pitel', 2008) its simulation model was created by authors in Matlab's Simulink environment (Fig. 2). The model regards with different dynamic characteristics of the PAM by inflation and deflation of compressed air into or from muscle. All variables (except of load force $F_{L}$ and pressure of the filling compressed air $p_{0}$ ) are zero at initial state of the system on Fig. 1 and Fig. 2, index number 1 pass for the first pneumatic artificial muscle PAM1 and index number 2 for the second pneumatic artificial muscle - PAM2, subscript $i$ pass for inflation of the muscle and subscript $o$ for deflation of the muscle.

By opening (control voltage $U_{i}$ ) of the appropriate inlet solenoid valve the air flow rate $Q_{i}$ will be on its output and will inflate the muscle after time delay $T_{d}$ in air supply line. Pressure $p$ in the muscle increases according to nonlinearity of PAM. This increasing pressure in the muscle backwardly expresses as differential pressure between input and output of the inlet solenoid valve. The magnitude of muscle contraction depends on the time of valve opening (after changeover of the control voltage $U_{i}$ to zero the muscle remains contracted in last position until reopening of the inlet valve).

By opening (control voltage $U_{o}$ ) of the appropriate outlet solenoid valve compressed air will deflate from muscle (air flow rate $Q_{o}$ ) either to partial or full deflation (depending on the time of valve opening by changeover of the control voltage $U_{o}$ to zero). Thus the pressure in muscle decreases. Position $\varphi$ of the actuator arm will be according to pressures $p_{1}, p_{2}$ in muscles, load force $F_{L}$ and actuator nonlinearity.

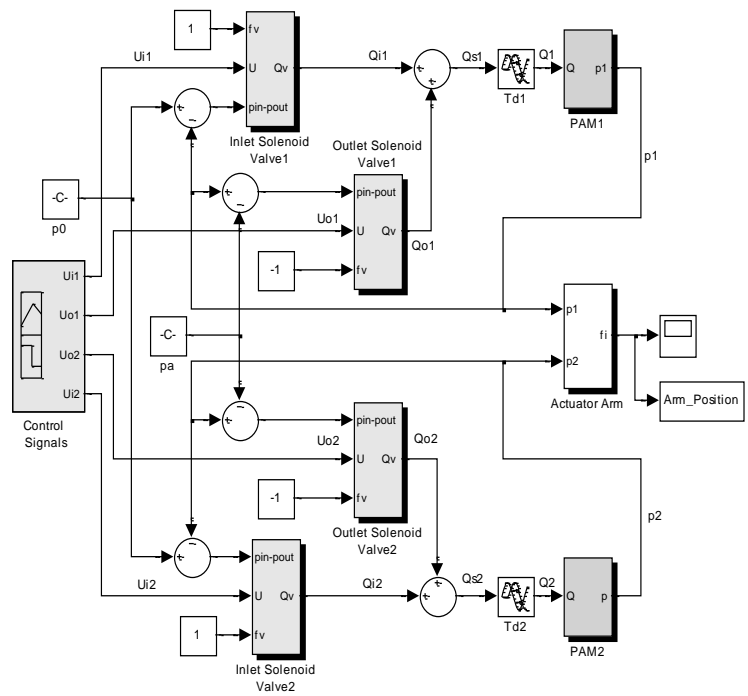

Fig. 2. Simulation model of PAM based actuator

\section{NONLINEARITIES IN MODEL}

There are three main nonlinearities in simulation model: solenoid valve nonlinearity, muscle nonlinearity and actuator nonlinearity.

\subsection{Solenoid valve nonlinearity}

The used solenoid valves have two working states: full open or full closed. Such valves can be mathematically described as nozzle which air flow rate depends on pressure difference in front of the valve and behind the valve:

$$
Q_{v}=C_{a} \cdot A_{v} \cdot \sqrt{p_{\text {in }}-p_{\text {out }}}
$$

where $Q_{v}$ is air flow rate through the valve, $C_{a}$ is aerodynamic correction coefficient, $A_{v}$ is valve area, $p_{\text {in }}$ is pressure in front of the valve (for inlet valve it is pressure of the filling compressed air, for outlet valve it is pressure in the muscle), $p_{\text {out }}$ is pressure 
behind the valve (for inlet valve it is pressure in the muscle, for outlet valve it is ambient pressure).

\subsection{Muscle nonlinearity}

Muscle nonlinearity characterizing dependence between pressure in muscle and air flow rate into or from a muscle is given by more nonlinearities (Líška \& Makovník, 2005):

- Dependence of pressure in the muscle on muscle volume can be found with help of equation for ideal gases, BoyleMariotte law and Bernoulli equation (Kerscher et al., 2006):

$$
\dot{P}=P_{a} \cdot \frac{f_{v} \cdot C_{a} \cdot A_{v} \cdot \sqrt{P_{\text {in }}-P_{\text {out }}}}{V}-P \cdot \frac{\dot{V}}{V}
$$

where $P$ is absolute muscle pressure, $P_{a}$ is absolute ambient pressure, $V$ is muscle volume, $f_{v}$ is coefficient describing the flow direction $\left(f_{v}=1\right.$ for inflation and $f_{v}=-1$ for deflation), $C_{a}$ is aerodynamic correction coefficient, $A_{v}$ is valve area, $P_{\text {in }}$ and $P_{\text {out }}$ are pressures different for inflation and deflation (for inflation $P_{i n}$ is absolute pressure of the filling compressed air and $P_{\text {out }}$ is absolute muscle pressure, for deflation $P_{\text {in }}$ is absolute muscle pressure and $P_{\text {out }}$ is absolute ambient pressure).

- Dependence of muscle volume on muscle contraction and dependence of muscle contraction on pressure in the muscle can be derived from geometric model of the PAM (Pitel', 2008):

$$
\begin{gathered}
V=\frac{b^{2} \cdot l_{0} \cdot(1-\kappa)-l_{0}^{3} \cdot(1-\kappa)^{3}}{4 \pi \cdot N^{2}} \\
\kappa=1-\sqrt{\frac{F_{L} \cdot 4 \pi \cdot N^{2}}{p \cdot 3 l_{0}^{2}}+\frac{b^{2}}{3 l_{0}^{2}}}
\end{gathered}
$$

where $V$ is muscle volume, $\kappa$ is relative muscle contraction, $F_{L}$ is load force of the muscle, $p$ is pressure in the muscle, $b, l_{0}, N$ are muscle parameters (Kerscher et al., 2006).

\subsection{Actuator nonlinearity}

Nonlinearity of the actuator is given by static characteristic of the actuator and describes dependence of actuator arm position on muscles pressures. Due to the complex elastic properties of the pneumatic muscles as well as the compressibility of the air, this characteristic is highly nonlinear (Fodor et al., 2010). The static characteristic was measured on realized actuator and approximated using Matlab's integrated Curve Fitting Tool. Regarding of shape and symmetry of measured characteristic the exponential function was found:

$$
\begin{aligned}
\varphi= & {\left[28,1225-27,148 \mathrm{e}^{-\left(p_{1}-p_{2}\right)}+4,658\left(p_{1}-p_{2}\right) \cdot \mathrm{e}^{-\left(p_{1}-p_{2}\right)}\right] . } \\
& {\left[\operatorname{sign}\left(p_{1}-p_{2}\right)\right], }
\end{aligned}
$$

which describes nonlinearity of the actuator (Hošovský, 2007).

\section{OBTAINED SIMULATION RESULTS}

The dynamic model of PAM based actuator was simulated in Matlab's Simulink environment with various time dependent control signals of the inlet (outlet) solenoid valves. For example as we can see on Fig. 3 at first by contemporaneous opening of the both inlet solenoid valves at time $t=0,5 \mathrm{~s}$ the actuator occupies zero position. After it by opening outlet solenoid valve SV_o1 at time $t=2 s$, compressed air from PAM1 will deflate from muscle with time delay and actuator arm occupies position $\varphi=-28,1^{\circ}$ according to nonlinearity of actuator. The same PAM1 will be inflated again at time $t=4 \mathrm{~s}$ to get zero position. Then at time $t=6 \mathrm{~s}$ outlet solenoid valve SV_o2 will be opened and actuator arm occupies position $\varphi=+28,1^{\circ}$. Finally actuator arm achieves zero position again by repeated inflation of PAM2.

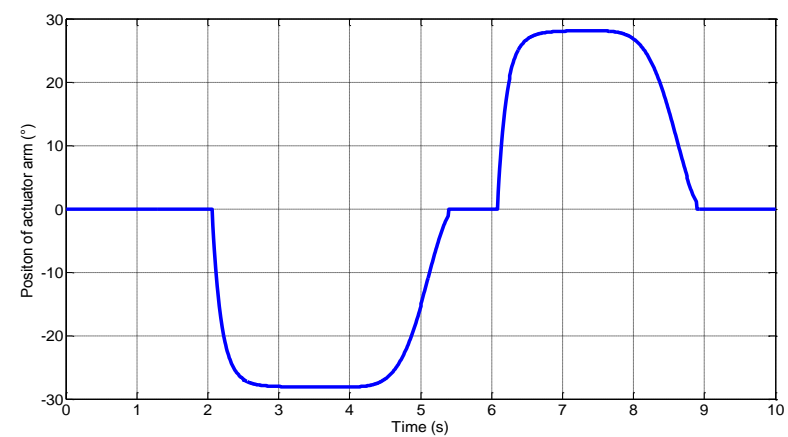

Fig. 3. Result of arm position simulation of PAM based actuator

\section{CONCLUSION}

It can be seen from result of simulation on Fig. 3 too, that dynamic characteristic of the actuator arm position is highly nonlinear. Therefore the control of such PAM based antagonistic actuator is complicated and requires to use advanced control algorithms for example from field of artificial intelligence. The designed model will be basis for development and simulation of these new control algorithms of pneumatic actuators based on artificial muscles.

\section{ACKNOWLEDGEMENTS}

The research work is supported by the Project of the Structural Funds of the EU „Research and development of intelligent nonconventional actuators based on artificial muscles", ITMS code: 26220220103.

\section{REFERENCES}

Balara, M. \& Balara, A. (2010). Rotary actuator with pneumatic artificial muscles. Strojárstvo EXTRA, Vol. XIV., No. 5/2010, pp. 46/1 - 46/3, ISSN 1335 - 2938

Balara, M. \& Boržíková, J. (2005). The mathematical description of characteristics of pneumatic artificial muscles. In: DAAAM International Scientific Book, Katalinic, B. (Ed.), pp. 025-032, DAAAM International Vienna, ISBN 3-901509-43-7, Vienna

Fodor, M., Šeminský, J., Veseliny, M., Židek, K. \& Župa, T. (2010). New Trends in Application of Artificial Muscles for Automation Devices used in Non-productive Sector. Manufacturing Engineering, Vol. IX., No. 4/2010, pp. 7880, ISSN 1335-7972

Hošovský, A. (2007). Numerical Approximation of Static Characteristic of PAM-based Antagonic Actuator. Journal of applied science in the thermodynamics and fluid mechanics, Vol. 1, No. 1/2007, pp. 1-4, ISSN 1802-9388

Kerscher, T.; Albiez, J.; Zollner J. M. \& Dillmann, R. (2006). Evaluation of the Dynamic Model Fluidic Muscles Using Quick-Release, Proceedings of First IEEE/RAS-EMBS International Conference on Biomedical Robotics and Biomechatronics BioRob 2006, February 20-22, 2006, Pisa, ISBN 1-4244-0040-6, pp. 637-642, IEEE

Líška, O. \& Makovník, R. (2005). Identification and Modelling of Dynamic Systems, Proceedings of Principia Cybernetica 2005, September 7-9, 2005, Ostrava, ISBN 80-248-0733-4, Farana, R. (Ed.), pp. 79-83, VŠB-TU, Ostrava

Pitel', J. (2008). Modelling of the PAM Based Antagonistic Actuator, Available from: http://www.cybletter.com/ index.php?pg=2\&s=2008-II Accessed: 2010-01-28 